\title{
Combination treatment with oncolytic Vaccinia virus and cyclophosphamide results in synergistic antitumor effects in human lung adenocarcinoma bearing mice
}

Elisabeth Hofmann ${ }^{1 \dagger}$, Stephanie Weibel ${ }^{1 \dagger}$ and Aladar A Szalay ${ }^{1,2,3,4,5^{*}}$

\begin{abstract}
Background: The capacity of the recombinant Vaccinia virus GLV-1h68 as a single agent to efficiently treat different human or canine cancers has been shown in several preclinical studies. Currently, its human safety and efficacy are investigated in phase I/II clinical trials. In this study we set out to evaluate the oncolytic activity of GLV-1h68 in the human lung adenocarcinoma cell line PC14PE6-RFP in cell cultures and analyzed the antitumor potency of a combined treatment strategy consisting of GLV-1h68 and cyclophosphamide (CPA) in a mouse model of PC14PE6-RFP lung adenocarcinoma.
\end{abstract}

Methods: PC14PE6-RFP cells were treated in cell culture with GLV-1h68. Viral replication and cell survival were determined by plaque assays and 3-(4,5-dimethylthiazol-2-yl)-2,5-diphenyltetrazolium bromide (MTT) assays, respectively. Subcutaneously implanted PC14PE6-RFP xenografts were treated by systemic injection of GLV-1h68, CPA or a combination of both. Tumor growth and viral biodistribution were monitored and immune-related antigen profiling of tumor lysates was performed.

Results: GLV-1h68 efficiently infected, replicated in and lysed human PC14PE6-RFP cells in cell cultures. PC14PE6-RFP tumors were efficiently colonized by GLV-1h68 leading to much delayed tumor growth in PC14PE6-RFP tumor-bearing nude mice. Combination treatment with GLV-1h68 and CPA significantly improved the antitumor efficacy of GLV-1h68 and led to an increased viral distribution within the tumors. Pro-inflammatory cytokines and chemokines were distinctly elevated in tumors of GLV-1h68-treated mice. Factors expressed by endothelial cells or present in the blood were decreased after combination treatment. A complete loss in the hemorrhagic phenotype of the PC14PE6-RFP tumors and a decrease in the number of blood vessels after combination treatment could be observed.

Conclusions: CPA and GLV-1h68 have synergistic antitumor effects on PC14PE6-RFP xenografts. We strongly suppose that in the PC14PE6-RFP model the enhanced tumor growth inhibition achieved by combining GLV-1h68 with CPA is due to an effect on the vasculature rather than an immunosuppressive action of CPA. These results provide evidence to support further preclinical studies of combining GLV-1h68 and CPA in other highly angiogenic tumor models. Moreover, data presented here demonstrate that CPA can be combined successfully with GLV-1 h68 based oncolytic virus therapy and therefore might be promising as combination therapy in human clinical trials.

Keywords: Vaccinia virus, Chemotherapy, Combination therapy, Cyclophosphamide, Lung cancer

\footnotetext{
* Correspondence: aaszalay@genelux.com

${ }^{\dagger}$ Equal contributors

'Department of Biochemistry, Biocenter, University of Wuerzburg, D-97074

Wuerzburg, Germany

${ }^{2}$ Rudolf Virchow Center, Research Center for Experimental Biomedicine,

University of Wuerzburg, D-97078, Wuerzburg, Germany

Full list of author information is available at the end of the article
}

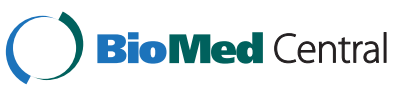

(c) 2014 Hofmann et al.; licensee BioMed Central Ltd. This is an Open Access article distributed under the terms of the Creative Commons Attribution License (http://creativecommons.org/licenses/by/2.0), which permits unrestricted use, distribution, and reproduction in any medium, provided the original work is properly credited. The Creative Commons Public Domain Dedication waiver (http://creativecommons.org/publicdomain/zero/1.0/) applies to the data made available in this article, unless otherwise stated. 


\section{Background}

Lung cancer still represents a very fatal disease causing the majority of the cancer-related deaths in males worldwide [1]. Non-small cell lung cancer (NSCLC), including adenocarcinoma, squamous cell carcinoma, and large cell carcinoma, constitutes $80-85 \%$ of all lung cancers, whereas small cell lung cancer accounts for $15 \%$ to $20 \%$, with most patients having advanced inoperable disease at the time of diagnosis. The current treatment options are surgical resection, platinum-based doublet chemotherapy, and radiation therapy alone or in combination [2]. However, the prognosis for lung cancer patients still remains poor with an overall 5-year survival rate of only 15\% [3]. Therefore, new, effective, therapeutic approaches for lung cancer are mandatory. One novel strategy represents the targeted therapy. Therein drugs are applied that specifically target genetic mutations and signalling pathways altered in lung cancer [4]. Up to now four targeted therapies have been FDA-approved for the treatment of lung cancer. Morevoer, the use of oncolytic viruses is a very promising therapeutic approach for the treatment of cancer. These viruses, either naturally occurring or genetically engineered, are replication-competent viruses that are able to selectively infect and destroy cancer cells either after intratumoral or systemic administration [5]. Among the most intensively investigated oncolytic viruses in preclinical or clinical studies are adenoviruses, herpes simplex virus, Newcastle disease virus, measles virus and Vaccinia virus [6-8]. Vaccinia virus (VACV) is a very promising agent for oncolytic virotherapy, since the use of VACV as a vaccine during the eradication of smallpox clearly demonstrated its safety in human patients. Furthermore, the broad host range, the efficient replication exclusively in the cytoplasm of host cells, the natural tropism for tumor tissues, and its large genome with a huge capacity for the integration of recombinant DNA are further advantages over other oncolytic viruses $[9,10]$. Until now, various oncolytic VACV have been investigated in preclinical and clinical studies [11]. Recently, it was shown that an oncolytic VACV, GLV-1h68, which was constructed by inserting gene expression cassettes for a Renilla luciferase-Aequora green fluorescent fusion protein (RUC-GFP), $\beta$-galactosidase and $\beta$-glucuronidase into the F14.5 L, J2R, and A56R loci, respectively, possesses reduced toxicity and enhanced tumor targeting specificity compared with its parental LIVP strain [12]. We have demonstrated that treatment with GLV-1h68 or its derivatives led to inhibition of tumor growth in several different xenograft models, including human breast cancer [12-14], anaplastic thyroid carcinoma [15], malignant pleural mesothelioma xenografts [16], squamous cell carcinoma [17], pancreatic carcinoma [18-21], prostate carcinoma [22-24], lung carcinoma [24], fibrosarcoma [25], hepatocellular carcinoma [26] as well as canine mammary adenoma [27] and carcinoma [28]. In addition, two clinical trials with GL-ONC1 (clinical grade
GLV-1h68) have been successfully started (http://www.clinicaltrials.gov; references NCT00794131 and NCT01443260).

Due to limitiations of oncolytic tumor therapy observed in several clinical studies, various approaches to enhance the efficiency of oncolytic viruses e.g. by combination with different cancer treatment modalities such as chemotherapy or radiotherapy are currently intensively investigated [29]. Improved results have been observed for GLV-1h68 using combinations with cisplatin or gemcitabine in pancreatic [18], mitomycin $C$ in prostate [23] or the $\beta$-galactosidaseactivatable prodrug seco-analog of duocarmycin SA in breast tumor xenografts [14]. Moreover, systemically delivered GLV-1h68 in combination with focal ionizing radiation (IR) resulted in improved tumor growth inhibition and mouse survival in a glioma tumor model [30].

Cyclophosphamide (CPA) is an alkylating agent that is known to cause crosslinking of DNA and is used for treatment of various tumors. CPA per se is an inactive prodrug that requires metabolic activation in the liver to become the active compound 4-hydroxycyclophosphamide. CPA has already been applied in combination with oncolytic viruses in various tumor models and its synergistic effects have been observed with Herpes simplex virus in glioma models [31-34], sarcoma [35] or in lung adenocarcinoma [36], with adenovirus in a hamster model of renal adenocarcinoma [37] and in cancer patients [38], with Reovirus in mouse melanoma $[39,40]$, and with VACV in a glioma xenograft model [41].

In this study, we set out to evaluate the oncolytic activity of GLV-1h68 in the human lung adenocarcinoma cell line PC14PE6 in cell culture, as well as to determine the antitumor potency of GLV-1h68 as monotherapy or in combination with CPA in a mouse model of PC14PE6-RFP lung adenocarcinoma. Our results demonstrate that GLV1 h68 is able to replicate in and kill human PC14PE6-RFP cells in cell culture. Furthermore, GLV-1h68 efficiently colonizes and notably delays the growth of PC14PE6-RFP tumors in a xenograft mouse model. Moreover, combination therapy with CPA and GLV-1h68 significantly improves the antitumoral efficacy of systemically injected GLV-1h68. Higher levels of pro-inflammatory cytokines and chemokines are seen in tumors of GLV-1h68-treated mice, while after CPA or combination treatment factors either expressed by endothelial cells or present in the blood are found to be reduced. Moreover, combination treatment led to a loss of the hemorrhagic phenotype of PC14PE6RFP tumors. Our results strongly suggest that the enhanced tumor control achieved by combining GLV-1h68 with CPA is due to an action of CPA on the tumor vasculature.

\section{Methods}

\section{Cell lines and virus strain}

Stably dsRed2-expressing human PC14PE6 cells were engineered and kindly provided by the group of F. Winkler 
(University of Heidelberg, Neurooncology, Heidelberg, Germany) in 2008 [42]. This PC14PE6-RFP cells were authenticated by the Leibniz-Institut DSMZ (Deutsche Sammlung von Mikroorganismen und Zellkulturen $\mathrm{GmbH}$, Braunschweig, Germany) to be identical with the parental cell line PC14 (Riken, Japan) in 2012. PC14PE6-RFP cells were maintained in DMEM (PAA Laboratories, Cölbe, Germany) supplemented with $10 \%$ fetal bovine serum (FBS), 2 mM GlutaMAX (both from Invitrogen $\mathrm{GmbH}$, Karlsruhe, Germany), $1 \times$ non-essential amino acids, $1 \times$ penicillin/streptomycin (both from PAA Laboratories) at $37^{\circ} \mathrm{C}$ under $5 \% \mathrm{CO}_{2}$. African green monkey kidney fibroblasts (CV-1; ATCC number CCL-70) were cultured in growth medium consisting of DMEM with $10 \% \mathrm{FBS}$ and 1x penicillin/streptomycin at $37^{\circ} \mathrm{C}$ under $5 \% \mathrm{CO}_{2}$. The attenuated Vaccinia virus strain GLV-1h68 was derived from LIVP (Lister strain from the Institute of Viral preparations, Moscow, Russia), as described previously [12].

\section{Viral replication assay}

For the viral replication assay, PC14PE6-RFP cells grown in 24-well plates were infected with GLV-1h68 at MOI 0.1 or 1.0 in infection medium (DMEM containing $2 \%$ FBS and supplements). After one hour of incubation at $37^{\circ} \mathrm{C}$ with gentle agitation every $20 \mathrm{~min}$, virus-containing supernatants were removed and replaced by fresh growth medium. After 24, 48 or $72 \mathrm{~h}$, cells and supernatants were harvested. Following three freeze-thaw cycles, serial dilutions of the lysates were titered by standard plaque assays on CV-1 cells. All samples were measured in triplicate.

\section{Cell viability assay}

To determine viral cytotoxicity, GLV-1h68 infected and uninfected PC14PE6-RFP cells in 24-well plates were analyzed using 3-(4,5-dimethylthiazol-2-yl)-2,5-diphenyltetrazolium bromide (MTT) assay. Cells were infected with GLV-1h68 at MOI 0.1 or 1.0 or mock-infected with infection medium (DMEM containing 2\% FBS and supplements). After one hour of incubation, virus-containing supernatants were removed by aspiration and fresh medium was added. After 24, 48 and 72 h, respectively, media were removed and $500 \mu \mathrm{l} \mathrm{MTT}(2.5 \mathrm{mg} / \mathrm{ml}$, SigmaAldrich, Germany) solution in DMEM without phenol red (PAA Laboratories, Cölbe, Germany) was added for $2 \mathrm{~h}$ at $37^{\circ} \mathrm{C}$ and $5 \% \mathrm{CO}_{2}$. MTT solution was then removed and $400 \mu \mathrm{l}$ of $1 \mathrm{~N} \mathrm{HCl}$ in isopropanol was added. Each sample $(3 \times 100 \mu \mathrm{l})$ was transferred to a 96-well plate and absorbance was measured at $570 \mathrm{~nm}$ with a reference wavelength of $650 \mathrm{~nm}$ in a Sunrise Microplate reader (Tecan, Austria). The percentage of cell survival was calculated using the following formula: \% cell survival = (absorbance value of infected cells/absorbance value of uninfected control cells) $\times 100 \%$.

\section{Human tumor xenografts and virus injections}

All animal experiments were performed in accordance with protocols approved by the government of Unterfranken (Wuerzburg, Germany, protocol number AZ 55.2-2531.0117/08) or by the Institutional Animal Care and Use Committee (IACUC) of Explora Biolabs (San Diego, USA, protocol number EB11-025). Human PC14PE6-RFP cells $\left(4 \times 10^{5}\right.$ cells in $100 \mu \mathrm{l}$ PBS $)$ were implanted subcutaneously into the right flank of six-week-old female nude mice (Hsd/ Athymic Nude-Foxn $1^{\text {nu }}$, Harlan Laboratories, Netherlands and Indianapolis). Tumor growth was monitored twice a week using a digital caliper. Tumor volume was calculated with the following formula: [(length $\times$ width $\left.\left.^{2}\right) \times 0.52\right]$. When tumors reached $100-200 \mathrm{~mm}^{3}$ mice were either injected via the tail vein with $1 \times 10^{7}$ pfu GLV-1h68 (in $100 \mu \mathrm{l} \mathrm{PBS}$ ) or PBS as control and/or combination treatment was started (day 0). For cyclophosphamide (CPA) combination treatment groups of infected or uninfected mice were injected intraperitoneally with $140 \mathrm{mg} / \mathrm{kg}$ bodyweight CPA (Sigma-Aldrich, Germany) at day 0 , and with $100 \mathrm{mg} / \mathrm{kg}$ bodyweight CPA at days $1,3,7,10,15,18$ and 21 .

\section{Virus titration from tumors and organs}

To assess viral distribution, PC14PE6-RFP tumor-bearing mice were either infected via tail vein with $1 \times 10^{7} \mathrm{pfu}$ of GLV-1h68 (in $100 \mu \mathrm{l}$ PBS) or subjected to combination treatment. At indicated time points, mice were sacrificed and tumors and organs were prepared and weighted. Tumors were homogenized in an gentleMACS Dissociator using M-Tubes (both Miltenyi Biotech $\mathrm{GmbH}$, Bergisch Gladbach, Germany) and organs in Precellys tubes (Peqlab, Erlangen, Germany) in a FastPrep ${ }^{\mathrm{TM}}$ FP120 (Thermo Electron Corporation, Langenselbold, Germany). After three freezethaw cycles, viral titers in homogenates were determined by standard plaque assays on $\mathrm{CV}-1$ cells.

\section{Fluorescence live-animal imaging}

Tumor cell growth and viral infection were monitored directly by optical imaging based on dsRed-expression by tumor cells and GFP-expression by virus infected cells respectively and quantified using a Maestro EX imaging system (CRI, Woburn, MA). Mice were anesthetized by isofluran inhalation (induction 4\%, maintenance 1\%). Images were taken at days 14 and 21 with a Maestro EX imaging system (CRi, Woburn, MA) using appropriate filters for dsRed (tumor, excitation: 503-555 nm, emission: $580 \mathrm{~nm}$ cut-in) and GFP (virus, excitation: 445-490 nm, emission: $515 \mathrm{~nm}$ cut-in). Images were evaluated and quantified using the Maestro Version 2.10.0 software.

\section{Rodent multi-analyte profile}

For preparation of tumor lysates, three mice of each group were sacrificed $7 \mathrm{dpi}$. Tumors were removed, resuspended 
in 9 volumes (W/V) lysis buffer $(50 \mathrm{mM}$ Tris- $\mathrm{HCl}$ $(\mathrm{pH} 7.4) ; 2$ mM EDTA (pH 7.4), $2 \mathrm{mM}$ PMSF and Complete Mini protease inhibitors (Roche, Mannheim, Germany) and lysed in an gentleMACS Dissociator using M-Tubes (both Miltenyi Biotech $\mathrm{GmbH}$, Bergisch Gladbach, Germany). Samples were then centrifuged at $500 \mathrm{~g}$ at $4^{\circ} \mathrm{C}$ for $5 \mathrm{~min}$ and supernatants were submitted to Rules-Based Medicine (Myriad RBM, Austin, USA) for bead-based immunodetection of mouse immune-related protein antigens (RodentMAP ${ }^{\oplus} \mathrm{v} 2.0$ ).

\section{Immunohistochemistry}

For immune-histochemistry, tumors were excised and snap-frozen in liquid $\mathrm{N}_{2}$, followed by fixation in $4 \%$ paraformaldehyde/PBS $\mathrm{pH} 7.4$ for $16 \mathrm{~h}$ at $4^{\circ} \mathrm{C}$. Fixed tumors were dehydrated in 10\% Sucrose/PBS for 3-4 h followed by $30 \%$ sucrose/PBS for $12 \mathrm{~h}$ and finally embedded in Tissue-Tek ${ }^{\bullet}$ O.C.T. (Sakura Finetek Europe B.V., Alphen aan den Rijn, Netherlands). Tumor samples were sectioned $(15 \mu \mathrm{m})$ with the cryostat 2800 Frigocut (Leica Microsystems $\mathrm{GmbH}$, Wetzlar, Germany) and stored at $-80^{\circ} \mathrm{C}$. Antibody-labeling was performed following fixation in ice-cold aceton. Endothelial cells were labelled with the hamster anti-mouse CD31 antibody (Chemicon, International, Temecula, CA) and Cy3-conjugated secondary donkey anti-hamster antibody obtained from Jackson ImmunoResearch (West Grove, PA). The primary antibody was incubated for $1 \mathrm{~h}$. After washing with PBS, sections were labeled for $30 \mathrm{~min}$ with the secondary antibody and finally mounted in Mowiol 4-88.

\section{Fluorescence microscopy}

The fluorescence-labelled preparations were examined using the Leica TCS SP2 AOBS confocal laser microscope equipped with an argon, helium-neon and UV laser and the LCS 2.16 software $(1024 \times 1024$ pixel RGB-color images). Digital images were processed with Photoshop 7.0 (Adobe Systems, Mountain View, CA) and merged to yield overlay images.

\section{Measurements of microvessel density}

The vascular density was determined in microscopic images ( $\times 20$ objective, $\times 10$ ocular) of CD31-labelled tumor sections. On the confocal microscope, the CD31 fluorescence was set to a clearly detectable level by adjusting the photo-multiplier before the images were captured. All images were decorated with five horizontal lines at identical positions using Photoshop 7.0 and all vessels which intersected these lines were counted to yield the vascular density. The vascular density was calculated in duplicate for ten images (five images of two different control, GLV-1h68-infected or combination-treated tumors) and presented as mean values with standard deviations.

\section{Statistics}

A two-tailed Student's t test was used for statistical analysis. $\mathrm{P}$ values of $<0.05$ were considered statistically significant.

\section{Results}

Human lung adenocarcinoma PC14PE6-RFP cells are permissive to infection with vaccinia virus GLV-1h68 In order to determine the infectivity of GLV-1h68 for the human lung adenocarcinoma cell line PC14PE6, we examined the kinetics of the GLV-1h68 replication in this cell line. Accordingly, PC14PE6-RFP cells were infected with GLV-1h68 (multiplicity of infection (MOI) 0.1 or $1.0)$, and a time-course analysis of viral replication was performed. A 2- to 3-fold logarithmic increase of GLV1 h68 titers in PC14PE6-RFP cells within 72 hours post infection (hpi) was observed at both MOIs (Figure 1A), demonstrating that the oncolytic Vaccinia virus GLV1 h68 is able to efficiently replicate within the human lung adenocarcinoma cells in cell culture. Next, we analyzed the oncolytic efficacy of GLV-1h68 on PC14PE6-RFP cells by a MTT cell viability assay. The results revealed that 24 hpi the number of surviving cells markedly decreased in an MOI-dependent manner. At $72 \mathrm{hpi}$, only $41+/-9.7 \%$ or $17+/-10.2 \%$ of cells survived the treatment at MOI 0.1 or 1.0 , respectively, demonstrating the considerable cytotoxic effect of GLV-1h68 on PC14PE6-RFP cells. Taken together, these data indicate that GLV-1h68 productively infects, replicates in and lyses human PC14PE6-RFP cells in cell culture, suggesting that GLV-1h68 has the potential to treat PC14PE6-RFP tumors in a mouse model.

\section{GLV-1h68 efficiently colonizes PC14PE6-RFP tumors in a xenograft mouse model}

Next, we investigated the biodistribution of systemically injected GLV-1h68 in PC14PE6-RFP tumor-bearing nude mice. For that, homogenates of tumors and organs from intravenously injected ( $1 \times 10^{7}$ plaque-forming units (pfu)) PC14PE6-RFP tumor-bearing mice $(n=4)$ were titered on CV-1 cells three, seven and 14 days after injection (Table 1). GLV-1h68 localized primarily to the tumors (in 4/4 mice per group) and was either not detectable (in liver, spleen) or found at notably lower titers in normal tissues (either in $1 / 4$ or $2 / 4$ mice, in lungs, ovaries or brain). Within three days post infection $3.5 \times 10^{7}+/-3.15 \times 10^{6} \mathrm{pfu}$ GLV-1h68/g tissue were found in tumors. The highest viral load in tumors was detected 14 days post infection, on average $3.44 \times 10^{8}+/-1.85 \times 10^{7} \mathrm{pfu} / \mathrm{g}$ tumor tissue. These data suggest that GLV-1h68 has a strong selectivity towards PC14PE6-RFP tumors in nude mice.

\section{GLV-1h68 treatment significantly delays tumor growth in PC14PE6-RFP bearing nude mice}

Due to the observed oncolytic effect of GLV-1h68 on PC14PE6-RFP cells in cell culture and the massive 


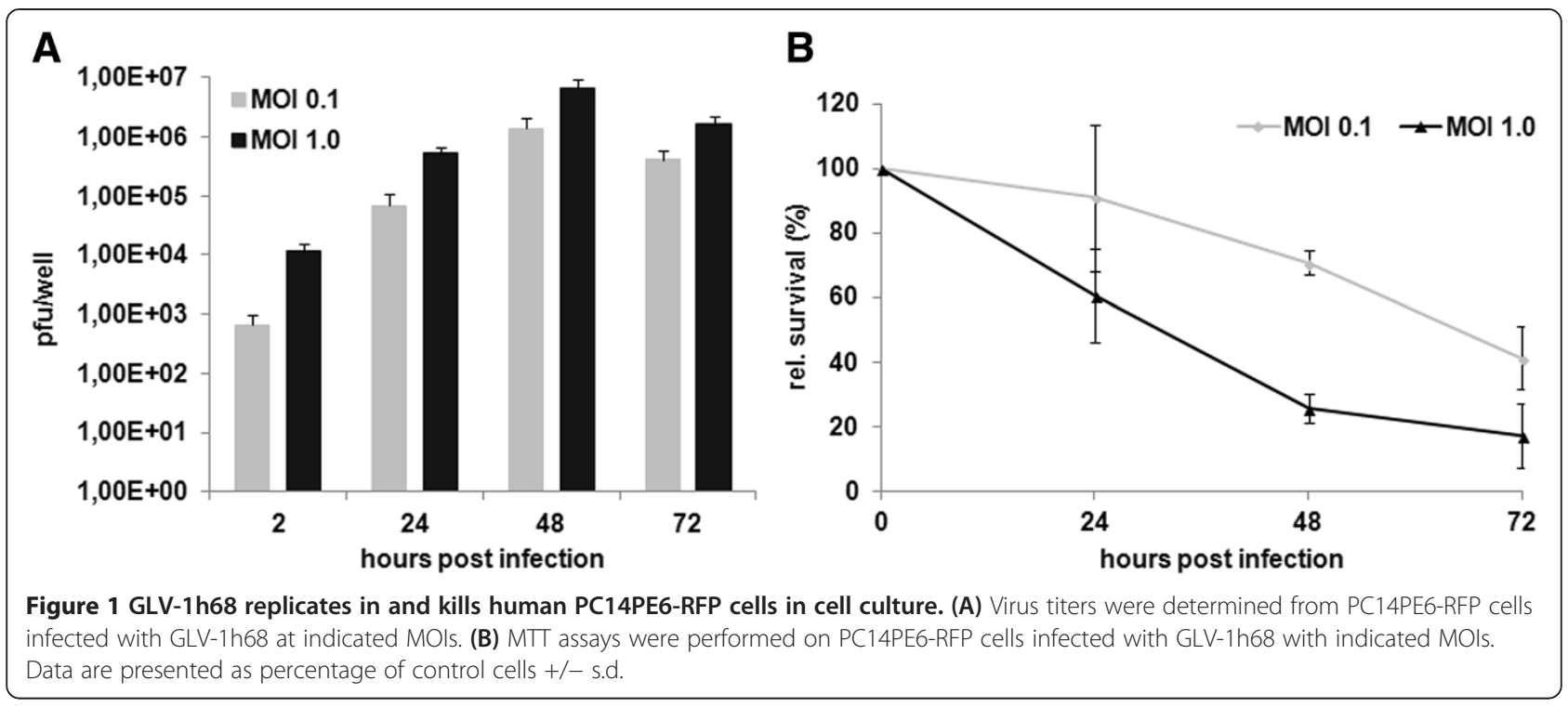

colonization of PC14PE6-RFP tumors with GLV-1h68, we analyzed the PC14PE6-RFP tumor growth response to oncolytic virotherapy with GLV-1h68 in vivo. For that, $4 \times 10^{5}$ PC14PE6-RFP cells were implanted s.c. into the right flank of nude mice. Tumor-bearing mice $(n=6)$ were i.v. injected with $1 \times 10^{7}$ pfu GLV-1h68 or with PBS as control. Tumor growth was monitored and already ten days post injection a significant tumor growth delay $(\mathrm{p}<0.01)$ of the GLV-1h68 treated group compared to the PBS group was observed (Figure 2). After this time point all mice of the control group had to be sacrificed due to high tumor burden. Despite an initial response to therapy, in the course of the experiment tumors of GLV-1h68-treated mice showed steadily tumor growth. Moreover, starting with day 20, individual mice of the

Table 1 Distribution of GLV-1h68 virus particles in tissues of PC14PE6-RFP tumor-bearing nude mice

\begin{tabular}{lccc}
\hline & \multicolumn{3}{c}{$\begin{array}{c}\text { Distribution of GLV-1 h68 in tissues of } \\
\text { PC14PE6-RFP tumor-bearing nude mice }\end{array}$} \\
\hline \multirow{3}{*}{ Tissue } & \multicolumn{3}{c}{$\mathbf{p f u / g}$ of tissue $(\mathbf{n}=\mathbf{4})$} \\
\cline { 2 - 4 } & $\mathbf{3} \mathbf{~ d p i}$ & $\mathbf{7 ~ d p i}$ & $\mathbf{1 4} \mathbf{~ d p i ~}$ \\
\hline Tumor & $3.5 \times 10^{7}+$ & $1.91 \times 10^{8}+$ & $3.44 \times 10^{8}+$ \\
& $/-3.15 \times 10^{6}(4 / 4)$ & $/-3.21 \times 10^{6}(4 / 4)$ & $/-1.85 \times 10^{7}(4 / 4)$ \\
Liver & 0 & 0 & 0 \\
Spleen & 0 & 0 & 0 \\
Lungs & 0 & $2.14 \times 10^{3}+$ & $5.04 \times 10^{1}+$ \\
& & $/-8.04 \times 10^{2}(1 / 4)$ & $/-1.22 \times 10^{1}(2 / 4)$ \\
Ovaries & 0 & $3.4 \times 10^{3}+$ & $9.61 \times 10^{3}+$ \\
& & $/-2.04 \times 10^{3}(1 / 4)$ & $/-1.86 \times 10^{4}(2 / 4)$ \\
Brain & 0 & 0 & $1.96 \times 10^{2}+$ \\
& & & $/-1.58 \times 10^{2}(1 / 4)$ \\
\hline
\end{tabular}

PC14PE6-RFP tumor-bearing nude mice $(n=4)$ were infected with $1 \times 10^{7}$ pfu of GLV-1h68. Three, seven and 14 days after infection, tumors and organs were harvested and viral titers were determined by standard plaque assays on CV-1 cells. Results are shown as mean pfu/g tissue or organ $+/-$ s.d.
GLV-1h68 treated group had to be taken out of the experiment due to excess tumor volume.

\section{Cyclophosphamide significantly improves the antitumoral} efficacy of systemically injected GLV-1h68

Since we have seen that treatment with GLV-1h68 leads to a significant tumor growth delay in the PC14PE6-RFP xenograft model but unfortunately neither tumor regression nor stable disease could be achieved by this therapy, we set out to improve the outcome of the therapy by combining oncolytic virotherapy with chemotherapy using cyclophosphamide (CPA). For that, nude mice bearing subcutaneously implanted PC14PE6-RFP tumors either received a single i.v. injection of $1 \times 10^{7} \mathrm{pfu}$ GLV-1h68 or an i.p. injection of $140 \mathrm{mg} / \mathrm{kg} / \mathrm{bw}$ CPA at day 0 , followed by multiple i.p. injections of $100 \mathrm{mg} / \mathrm{kg} / \mathrm{bw}$ every 3-4 days during the whole experiment or a combination of viro- and chemotherapy $(n=5$; Figure $3 A)$. In PBS treated control mice rapid tumor growth was observed, reaching the tumor end point between ten and 14 days post treatment initiation (Figure 3B). Therapy with CPA alone resulted in a slight delay of tumor growth compared to control mice. Treatment with oncolytic GLV-1h68 resulted in a more pronounced tumor growth retardation being significant from day seven post injection on $(\mathrm{p}<0.05$, day $7 ; \mathrm{p}<0.01$, day 10$)$. Mice of this group reached highest acceptable tumor volumes on day 28 after start of therapy. In marked contrast, combination treatment showed an impressive antitumor activity. The tumor growth retardation after combination treatment was significant compared to the PBS control group starting day seven ( $\mathrm{p}<0.05$, day $7 ; \mathrm{p}<0.01$, day 10 ) and compared to CPA alone from 14 days post injection on $(\mathrm{p}<0.05$, days 14 and 17). Even more, beginning with day 21 combination treatment had a significant better effect on the growth of 


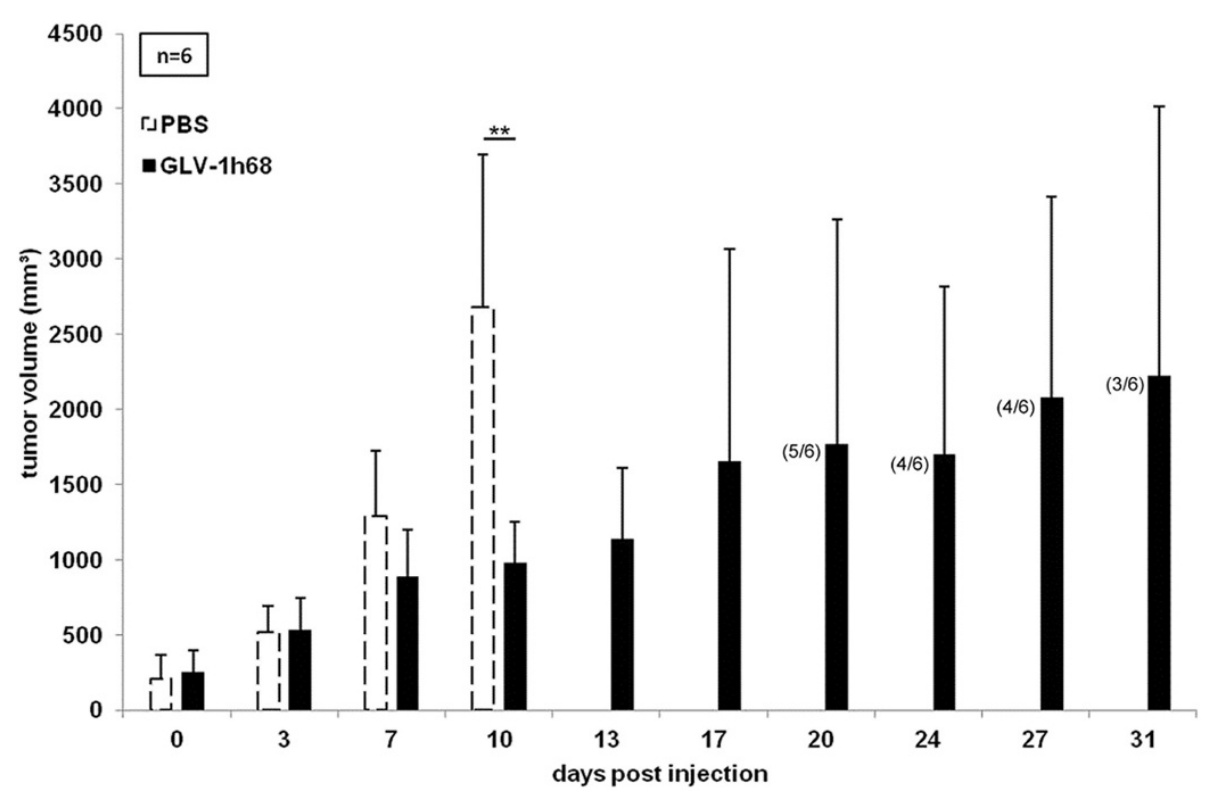

Figure 2 Treatment of PC14PE6-RFP xenografts by a single i.v. injection of GLV-1h68. $4 \times 10^{5}$ PC14PE6-RFP cells were implanted subcutaneously into the right flank of female nude mice. When tumor volumes reached approximately 200-250 $\mathrm{mm}^{3}$ mice were randomized into two groups $(n=6)$. Mice were either treated with an i.v. injection of $1 \times 10^{7}$ pfu GLV-1h68 or received PBS as control (day 0). Numbers of surviving mice are indicated in parentheses.
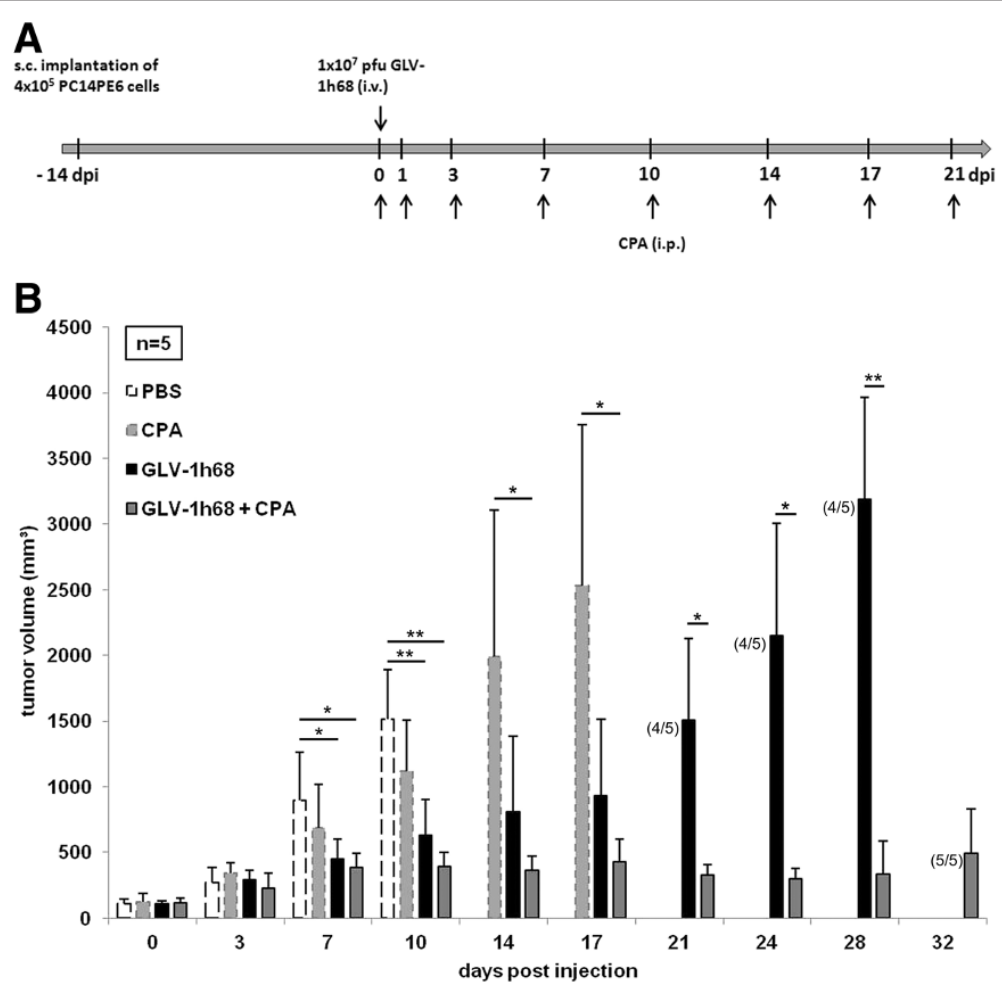

Figure 3 Combination treatment of PC14PE6-RFP tumor-bearing nude mice with GLV-1h68 and cyclophosphamide. (A) Treatment schedule demonstrating the regimen of GLV-1h68 and CPA treatment in PC14PE6-RFP tumor-bearing mice. (B) Tumor volumes of PC14PE6-RFP tumors treated with or without combination treatment. $4 \times 10^{5}$ PC14PE6-RFP cells were implanted subcutaneously into the right flank of female nude mice. When tumor volumes reached approximately 100-130 $\mathrm{mm}^{3}$ mice were randomized into four groups $(n=5)$. Mice were either treated with a single i.v. injection of $1 \times 10^{7} \mathrm{pfu}$ GLV-1h68, with multiple i.p. injections of CPA, a combination of both or with PBS as control. Numbers of surviving mice are indicated in parentheses. 
PC14PE6-RFP tumors than therapy with GLV-1h68 alone ( $\mathrm{p}<0.05$, days 21 and 24; $\mathrm{p}<0.01$, day 28) with stable tumor volume until 32 days. Over the course of the experiment no evident toxicity by either treatment was seen, as confirmed by monitoring of body weight (data not shown). These results demonstrate that CPA in combination with GLV-1h68 acts synergistically in PC14PE6-RFP xenografts and is promising for future clinical applications.

\section{Treatment with CPA does not alter viral titers in tumors and organs of nude mice}

To address whether the increased antitumor efficacy of the combination therapy is associated with higher viral titers in the tumors or CPA exerts an immunosuppressive effect in our experimental model possibly resulting in elevated viral load in organs, we prepared tumors and organs of GLV-1h68-treated as well as GLV-1h68- and CPA-treated mice 21 days post infection and determined titers by plaque assays. Interestingly, combination treatment does not significantly alter the amounts of viral particles in the tumor compared to treatment with GLV-1h68 alone (Table 2). Furthermore, we did not see increased viral titers in the organs of mice after combination treatment, suggesting that in our experimental model treatment with CPA has no immunosuppressive effect leading to systemic infection with Vaccinia virus.

\section{CPA treatment results in infection of larger tumor areas}

To analyze the intratumoral viral distribution as well as the extent of the viral tumor infection, we investigated live tumor-bearing mice 14 and 21 days after beginning of treatment by fluorescence imaging (Figure 4A and B). For this, the tumor mass was measured via the RFP fluorescence of the tumor cells and the viral infection was determined by GFP expression. The RFP signals

Table 2 Distribution of GLV-1h68 virus particles in tissues of PC14PE6-RFP tumor-bearing nude mice treated with GLV-1h68 or GLV-1h68/CPA

\begin{tabular}{ccc}
\hline \multicolumn{2}{c}{ Distribution of GLV-1 $\mathbf{h 6 8}$ in tissues of PC14PE6-RFP tumor-bearing } \\
nude mice, $\mathbf{2 1} \mathbf{~ d p i}$
\end{tabular}

PC14PE6-RFP tumor-bearing nude mice $(n=3)$ were either infected solely with $1 \times 10^{7}$ pfu of GLV-1h68 or infected with GLV-1h68 and received simultaneous treatment with CPA. 21 days after infection, tumors and organs were harvested and viral titers were determined by standard plaque assays on CV-1 cells. Results are shown as mean $\mathrm{pfu} / \mathrm{g}$ tissue or organ $+/-$ s.d. obtained by fluorescence imaging (Figure 4C) correlated well with tumor size measurements shown in Figure 3. Twenty-one days post infection GFP signals in GLV1h68-treated mice were similar to the combination group confirming the results found by plaque assays of homogenized tumors (Table 2). Finally, the percentage of infected tumor mass was calculated (Figure 4D). Strikingly, combination treatment leads to a higher percentage of the tumor mass infected (55.68\%) compared to monotherapy with GLV-1h68 (22.48\%) 21 dpi. Thus, simultaneous treatment with CPA led to a more pronounced viral distribution within the tumor tissue and, therefore, contingently, to a better oncolytic effect in PC14PE6-RFP tumors.

\section{Analysis of the host immune response upon treatment with virus and/or CPA}

Since CPA is known as a broad immunosuppressive agent, we investigated the host immune response to virus infection and/or CPA treatment 7dpi in PC14PE6-RFP tumor-bearing mice. We are aware of the fact that nude mice lack adaptive immunity and results obtained by these experiments might not be directly transferred to immunocompetent humans. Nevertheless, we used the nude mouse model since we wanted to study the oncolytic effect of Vaccinia virus on a lung adenocarcinoma of human origin. By protein profiling we found that expression levels of several cytokines and chemokines were significantly elevated in tumors of GLV-1h68-treated mice compared to untreated controls (Table 3A). The majority of these cytokines and chemokines, like eotaxin, IL-7, MIP-1 beta, MCP-1, MCP-3, MCP-5, or TNF-alpha, and even Myeloperoxidase secreted by neutrophils and tissue macrophages, create a pro-inflammatory microenvironment in the target tissues. The only protein that was found to be down-regulated upon viral infection was EGF, a growth factor stimulating the growth of epidermal or epithelial tissues and some fibroblasts.

Combination treatment leads to significant up-regulation of M-CSF-1, MCP-1 and MCP-5 (pro-inflammatory) and down-regulation of Apo A-I (anti-inflammatory) and EGF (Table 3B) compared to untreated controls. Interestingly, levels of VCAM-1 (expressed on endothelial cells during inflammation) and coagulation factors Fibrinogen and vWF are also significantly decreased after combination treatment.

Compared to CPA treatment alone, infection with GLV1 h68 or combination treatment leads to up-regulation of several pro-inflammatory cytokines and chemokines (Table 3C and D), like seen in the virus-treated versus untreated tumors, affirming that virus infection results in a pro-inflammatory status within the tumor. Moreover, compared to monotherapy with CPA, VCAM-1 is decreased upon combination treatment. Interestingly, after 


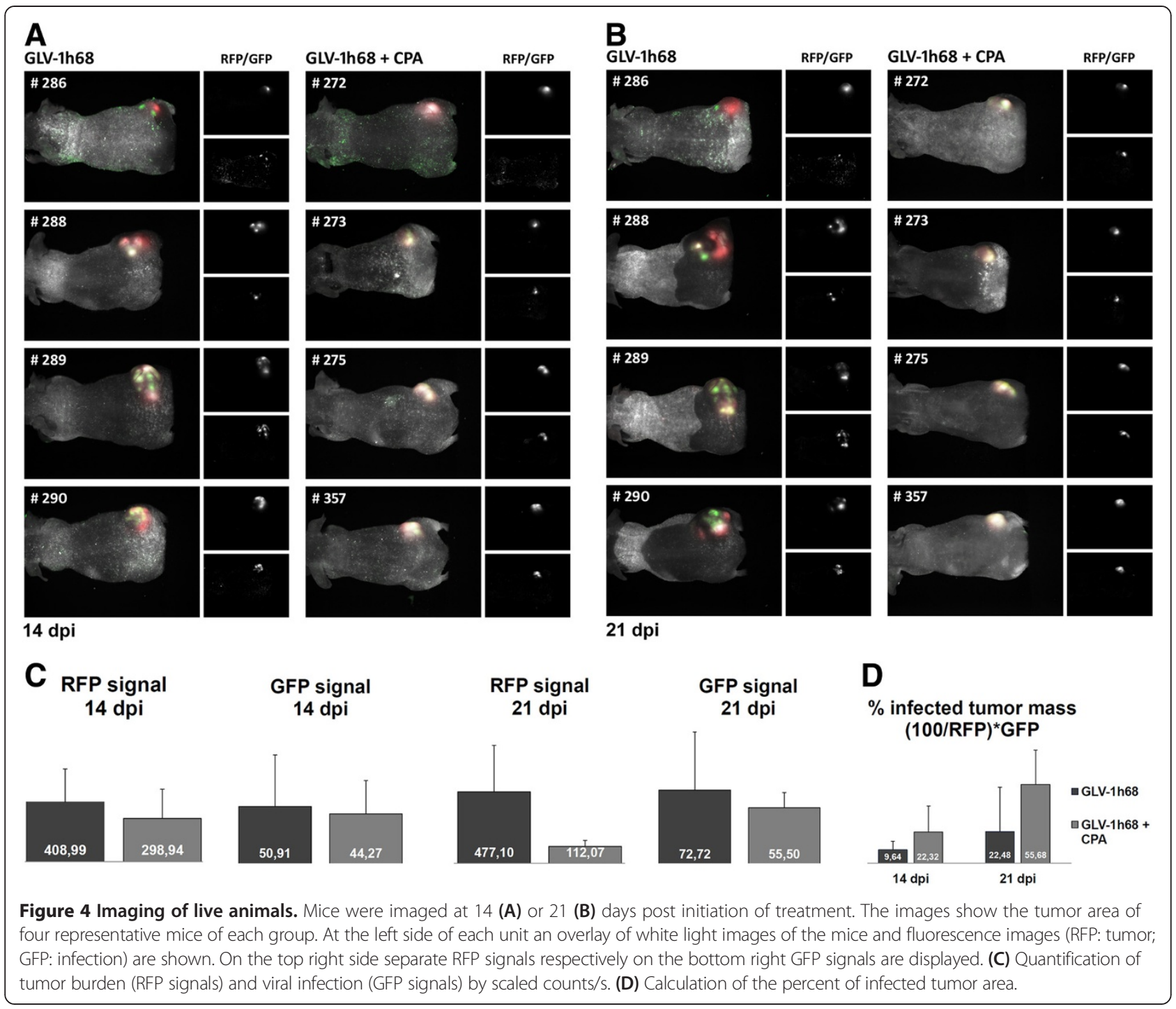

CPA or combination therapy lower levels of the von Willebrand factor (vWF) are found (Table 3B, E and F).

The hemorrhagic phenotype of PC14PE6-RFP tumors disappears after combination treatment

We further could observe that especially untreated subcutaneously implanted PC14PE6-RFP tumors but also GLV-1h68- or CPA-treated tumors had a hemorrhagic phenotype $7 \mathrm{dpi}$ (Figure 5A), in striking contrast to tumors after combination treatment, which appeared either white or skin-colored. Notably, at the time point of infection, tumors of the combination group have already been slightly blue demonstrating that by treatment with GLV-1h68 in combination with CPA, tumors lose their hemorrhagic phenotype. We finally analyzed the vascular density by CD31 staining of tumor sections $7 \mathrm{dpi}$. Indeed, there was a decrease in the number of blood vessels after CPA and combination treatment compared to GLV-1h68-treated tumors (Figure 5B), albeit this was not significant.

\section{Discussion}

The efficiency of the oncolytic VACV GLV-1h68 in treating different human or canine cancers in mice has been demonstrated in several preclinical studies [12-28]. Moreover, currently two clinical trials with GLV-1h68 as intervention are carried out (http://www.clinicaltrials.gov). One great advantage of oncolytic viruses for the treatment of cancers comprises their capability to specifically kill cancerous cells whereas normal cells are not affected. In the current study, we investigated the effect of a combined treatment strategy consisting of oncolytic VACV GLV-1h68 and the alkylating agent CPA on the growth of human lung adenocarcinoma PC14PE6 xenografts. Synergistic effects of diverse oncolytic viruses and CPA have been described in the literature [31-41]. Suggested mechanisms are, if specified, mostly due 
Table 3 Comparison of mouse immune-related protein profiling in PC14PE6-RFP-derived tumors at day seven after treatment begin $(n=3)$

\begin{tabular}{|c|c|c|}
\hline Antigen names & Ratios $^{a}$ & Classification \\
\hline \multicolumn{3}{|l|}{ (A) GLV-1h68/PBS } \\
\hline Eotaxin & $9.34^{*}$ & Proinflammatory chemokine \\
\hline Interleukin-11 (IL-11) & $1.90^{*}$ & Cytokine \\
\hline Interleukin-2 (IL-2) & $1.97^{*}$ & Cytokine \\
\hline Interleukin-7 (IL-7) & $1.63^{*}$ & Proinflammatory cytokine \\
\hline Macrophage Inflammatory Protein-1 beta (MIP-1 beta) & $3.76^{*}$ & Proinflammatory chemokine \\
\hline Monocyte Chemotactic Protein 1 (MCP-1) & $18.30^{* *}$ & Proinflammatory chemokine \\
\hline Monocyte Chemotactic Protein 3 (MCP-3) & $11.12^{* *}$ & Proinflammatory chemokine \\
\hline Monocyte Chemotactic Protein-5 (MCP-5) & $27.85^{*}$ & Proinflammatory chemokine \\
\hline Myeloperoxidase (MPO) & $3.99^{* *}$ & Peroxidase enzyme \\
\hline Oncostatin-M (OSM) & $1.99 *$ & Cytokine \\
\hline Tumor Necrosis Factor alpha (TNF-alpha) & $2.05^{*}$ & Proinflammatory cytokine \\
\hline Epidermal Growth Factor Mouse (EGF Mouse) & $0.54^{*}$ & Growth factor \\
\hline \multicolumn{3}{|l|}{ (B) GLV-1h68 + CPA/ PBS } \\
\hline Macrophage Colony-Stimulating Factor-1 (M-CSF-1) & $1.69^{*}$ & Proinflammatory cytokine \\
\hline Monocyte Chemotactic Protein 1 (MCP-1) & $20.16^{*}$ & Proinflammatory chemokine \\
\hline Monocyte Chemotactic Protein-5 (MCP-5) & $30.60^{*}$ & Proinflammatory chemokine \\
\hline Apolipoprotein A-I (Apo A-I) & $0.17^{*}$ & Anti-inflammatory protein \\
\hline Epidermal Growth Factor Mouse (EGF Mouse) & $0.54^{*}$ & Growth factor \\
\hline Fibrinogen & $0.52^{*}$ & Blood coagulation \\
\hline Vascular Cell Adhesion Molecule-1 (VCAM-1) & $0.45^{*}$ & Cell-cell adhesion \\
\hline von Willebrand factor (vWF) & $0.39 *$ & Blood coagulation \\
\hline \multicolumn{3}{|l|}{ (C) GLV-1h68/CPA } \\
\hline Eotaxin & $12.43^{*}$ & Proinflammatory chemokine \\
\hline Granulocyte Chemotactic Protein-2 Mouse (GCP-2 Mouse) & $2.51^{*}$ & Proinflammatory chemokine \\
\hline Growth-Regulated Alpha Protein (KC/GRO) & $2.96^{*}$ & Proinflammatory chemokine \\
\hline Interleukin-10 (IL-10) & $2.74^{*}$ & Cytokine \\
\hline Interleukin-12 Subunit p70 (IL-12p70) & $2.11^{*}$ & Pleiotropic cytokine \\
\hline Macrophage Inflammatory Protein-1 beta (MIP-1 beta) & $3.06^{*}$ & Proinflammatory chemokine \\
\hline Macrophage Inflammatory Protein-3 beta (MIP-3 beta) & $2.90^{* *}$ & Proinflammatory chemokine \\
\hline Matrix Metalloproteinase-9 (MMP-9) & $2.30^{*}$ & Enzyme \\
\hline Monocyte Chemotactic Protein 1 (MCP-1) & $9.76^{* *}$ & Proinflammatory chemokine \\
\hline Monocyte Chemotactic Protein 3 (MCP-3) & $5.90^{* *}$ & Proinflammatory chemokine \\
\hline Monocyte Chemotactic Protein-5 (MCP-5) & $20.97^{*}$ & Proinflammatory chemokine \\
\hline \multicolumn{3}{|l|}{ (D) GLV-1h68 + CPA/CPA } \\
\hline Granulocyte Chemotactic Protein-2 Mouse (GCP-2 Mouse) & $3.05^{*}$ & Proinflammatory chemokine \\
\hline Interleukin-6 (IL-6) & $5.01^{*}$ & Cytokine \\
\hline Monocyte Chemotactic Protein 1 (MCP-1) & $10.75^{*}$ & Proinflammatory chemokine \\
\hline Monocyte Chemotactic Protein-5 (MCP-5) & $23.04^{*}$ & Proinflammatory chemokine \\
\hline Serum Amyloid P-Component (SAP) & $1.38^{*}$ & Acute phase reactant \\
\hline T-Cell-Specific Protein RANTES (RANTES) & $3.32^{*}$ & Proinflammatory chemokine \\
\hline Tissue Inhibitor of Metalloproteinases 1 Mouse (TIMP-1 Mouse) & $2.56^{*}$ & Protein inhibitor \\
\hline Vascular Cell Adhesion Molecule-1 (VCAM-1) & $0.78^{*}$ & Cell-cell adhesion \\
\hline
\end{tabular}


Table 3 Comparison of mouse immune-related protein profiling in PC14PE6-RFP-derived tumors at day seven after treatment begin $(\mathbf{n}=3)$ (Continued)

(E) CPA/PBS

von Willebrand factor (VWF)

$0.48^{*}$

Blood coagulation

(F) GLV-1h68 + CPA/GLV-1h68

von Willebrand factor (VWF)

$0.55^{* *}$

Blood coagulation

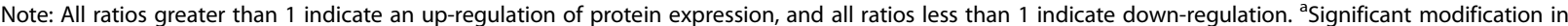
protein ratios with ${ }^{*} p<0.05, * * p<0.01,{ }^{* * *} p<0.001$, Student's t -test.

to the immuno-modulatory properties of CPA. CPA is known to suppress the host innate immunity and inhibition of intratumoral infiltration of mononuclear cells has been described, thus probably extending the survival of the virus within the tumors [33,36,37]. When used in a low- dose metronomic (LDM) schedule, CPA can also, exert antiangiogenic effects [43-45].This seems to be based on the induction of thrombospondin-1 which in turn probably acts antiangiogenic through binding to CD36 [46] or through binding and sequestering VEGF [47].

In our study, we could show that combination therapy with GLV-1h68 and CPA led to a significant growth inhibition of PC14PE6-RFP xenografts compared to GLV1 h68 alone from day 21 post injection on (Figure 3B). Analysis of the viral load of combination-treated or GLV1h68-treated tumors revealed that the better therapeutic effect was not due to an enhanced viral titer in the tumors.
Moreover, after combination treatment we did not see enhanced viral titers in the organs of mice suggesting that CPA has no immunosuppressive effect in our experimental model. Immune-related effects of the investigated therapy were not explored in detail in the present study. However, preliminary data obtained by histological analysis of CPA- and non-CPA-treated tumors 7 dpi revealed no significant difference in the content of CD68-positive immune cells, e.g. monocytes/macrophages (Additional file 1). Furthermore depletion of phagocytic cells especially monocytes and macrophages by clodronate liposomes did result in lesser tumor growth retardation than by treatment with CPA alone (Additional file 2). Both observations are again hinting that CPA has no effect on cells of monocytic origin in the PC14PE6-RFP model. By protein profiling of lysates of untreated, CPA-, GLV-1h68- and combination treated tumors, we found the expression of
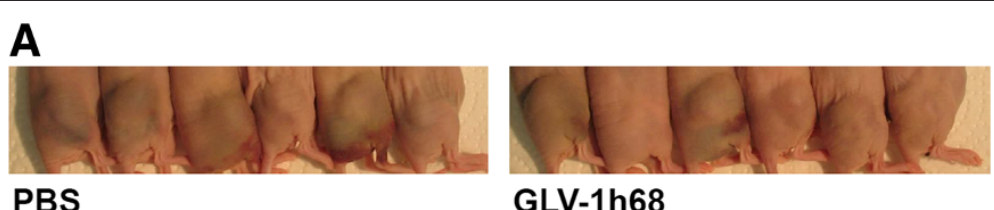

GLV-1h68
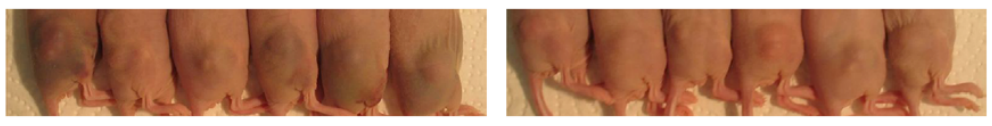

CPA

GLV-1h68 + CPA

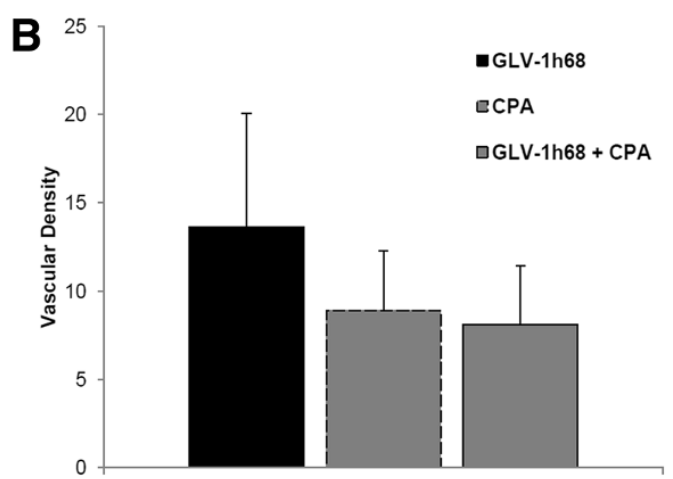

Figure 5 Phenotypes of s.c. implanted PC14PE6-RFP tumors and number of CD31-positive blood vessels. (A) Photographic images of subcutaneously implanted PC14PE6-RFP tumors were taken 7 days post PBS-, GLV-1h68-, CPA- or combination treatment begin. (B) Vascular density was measured in CD31-labelled cross-sections of GLV-1h68-, CPA- or combination treated tumors 7 days after treatment start. Shown are the mean values $+/-$ s.d. 
several pro-inflammatory cytokines and chemokines of host origin to be up-regulated in tumor tissues after virus infection and even after combination treatment, although to a lesser extent (Table 3). The majority of these cytokines/chemokines and pro-inflammatory proteins, like eotaxin, MIP-1 beta, MCP-1, MCP-3, MCP-5, TNF-alpha, and $\mathrm{MPO}$ are known to be produced by activated macrophages in the inflamed tissue. Similar results also have been obtained in xenograft models of human pancreatic [18], prostate [22] and hepatocellular [26] as well as canine mammary carcinomas [28] suggesting that it is a general mechanism of GLV-1h68 to induce strong innate host immune responses in tumors of different origins. It is also very interesting to note that after virus infection or combination treatment the CCR5 ligands MIP-1 beta/ MIP-3 beta or RANTES, respectively, are overexpressed. The CCR5 ligand chemokine pathway is, among other molecular pathways, known to be consistently activated during immune-mediated cancer rejection as well as other immune-mediated tissue destruction processes, as described in the "Immunologic Constant of Rejection (ICR)" [48]. The cytokine Oncostatin-M, which is up-regulated after VACV infection, belongs to the IL- 6 family and has cytostatic activities on a number of tumor cell lines [49-51]. The only protein that was found to be down-regulated upon viral infection was EGF. Interestingly, mutations of the EGF receptor (EGFR) have been associated with several types of cancers, including lung cancer, and targeted therapy using small molecules disrupting kinase activity of EGFR results in considerable clinical benefit in lung cancer patients [4]. Moreover, Goswami et al. [52] described a paracrine loop between breast carcinoma cells (producing CSF) and macrophages (producing EGF) leading to increased carcinoma cell invasion and they suggested that disabling this loop might result in clinical benefit in the treatment of cancer. So, it is remarkable that by virotherapy with Vaccinia virus endogenous EGF levels are reduced possibly resulting in inhibition of downstream pro-survival signaling pathways or inhibition of tumor cell invasion.

Combination treatment of GLV-1h68 and CPA leads to significant up-regulation of M-CSF-1, MCP-1 and MCP-5, which have pro-inflammatory activities (Table 3B) and again to down-regulation of EGF compared to untreated controls. Concentrations of Apo A-I, VCAM-1, Fibrinogen and vWF are found to be decreased after combination treatment. Apo A-I has anti-inflammatory [53,54] but also anti-thrombotic [55] activities. VCAM-1 is expressed by the cytokine-activated endothelium and mediates leukocyte-endothelial cell adhesion. It is also known that in several types of cancers VCAM-1 is aberrantly expressed on the surface of tumor cells thereby tethering macrophages to tumor cells and generating favorable conditions for tumor angiogenesis, invasion and metas- tasis [56,57]. Recently, a study reported about an EGFenhanced VCAM-1 expression promoting macrophage and glioblastoma cell interaction and tumor cell invasion [57]. In another work a VCAM-1-mediated tumor immune evasion has been described $[58,59]$. The authors found that overexpression of VCAM- 1 by cancer cells led to decreased apoptosis of tumor cells and a significant decrease in the number of tumor-infiltrating CD8+ T cells expressing VCAM-1. Therefore, reduction of VCAM-1 and EGF by combination treatment might have favorable effects in terms of inhibition of tumor cell invasion and tumor immune evasion. Fibrinogen plays a pivotal role in the coagulation cascade. vWF is synthesized by endothelial cells and megakaryocytes and promotes the adhesion of platelets to sites of vascular injury. Interestingly, the latter four factors, Apo A-I, VCAM-1, Fibrinogen and vWF, which are found to be decreased after combination treatment, are either expressed by endothelial cells or are present in the blood, hinting that combination therapy has an effect on the tumor vasculature in the PC14PE6RFP model. Compared to CPA treatment alone, infection with GLV-1h68 or combination treatment leads to an up-regulation of several pro-inflammatory cytokines and chemokines (Table $3 \mathrm{C}$ and $\mathrm{D}$ ), like seen in the virus-treated versus untreated tumors, affirming that virus infection leads to a pro-inflammatory status within the tumor. Moreover, compared to monotherapy with CPA, lower levels of VCAM-1 are observed upon combination treatment. Interestingly, after CPA or combination therapy the only protein that was found to be significanlty decreased compared to respective controls was vWF (Table 3E and F). This indicates that the primary effect of CPA in this model is caused by an effect on the vasculature and not by alteration of the immune response. However, it is speculating to assume if the lower levels of these factors are due to a down-regulation on the level of protein expression or are a result of the lower density of blood vessels found in tumors after CPA or combination treatment.

Taken together, these data show that pro-inflammatory cytokines and chemokines are elevated in PC14PE6-RFP tumors of GLV-1h68-treated mice (Table 3A, B, C, and D). But more importantly, levels of factors either expressed by endothelial cells or present in the blood are found to be decreased after CPA or combination treatment (Table 3B, D, $\mathrm{E}$, and F). We therefore suppose that in the PC14PE6-RFP model the enhanced tumor growth inhibition observed after combination therapy is due to an effect on the vasculature rather than an immunosuppressive action of CPA. However, it is conceivable that the modulation of the vasculature may alter the following immunological response to VACV e.g. by hampering immune recruitment to the tumor site.

Especially untreated PC14PE6-RFP tumors, but also GLV-1h68 or CPA-treated tumors have a hemorrhagic 
phenotype (Figure 5A). This seems to be a hallmark of the PC14PE6 cell line since Yano et al. already described the development of bloody pleural effusions after i.v. injection of PC14PE6 cells [60]. Only recently, Weibel et al. showed that after subcutaneous implantation of PC14PE6 cells malignant effusion concomitant hematoma formation occurs at the tumor site, and, during oncolytic virotherapy using GLV-1h68 and especially its derivative GLV-1h108, which encodes a single chain antibody against VEGF, tumor-associated hematoma disappeared [61]. Remarkably, in the present study we could show that after combination treatment PC14PE6-RFP tumors lose their hemorrhagic phenotype. Since at the time point of treatment start, tumors of the combination group already showed a slight blue color, CPA treatment seems not only to prevent the development of the hematoma but to actively rebuild a non-hemorrhagic appearance when used in combination with oncolytic Vaccinia virus GLV1h68. This additionally indicates that in the PC14PE6-RFP xenograft model combination therapy with GLV-1h68 and CPA acts on the tumor vasculature. To further support this hypothesis, we analyzed the vascular density in CD31-labelled tumor cross-sections $7 \mathrm{dpi}$. Indeed, there was a decrease in the number of blood vessels after CPA and combination treatment compared to GLV-1h68treated tumors (Figure 5B), albeit this was not significant. The presence of CD31-positive blood vessels after CPA treatment, further suggest that CPA seems to have no immunosuppressive effect, since CD31 is involved in leukocyte trafficking to sites of inflammation. Previous work in our laboratory demonstrated that GLV-1h68 does not destroy endothelial cells in tumors and that the tumor vasculature in infected tumors is still functional [62]. In the matter of the significance of tumor vasculature in tumor progression, therapeutic approaches additionally targeting the tumor endothelium may contribute to a better therapeutic outcome. Therefore, combination strategies composed of an agent, which directly kills tumor cells on the one hand (in our case GLV-1h68), and an additional therapeutics, which targets normal cells within the tumors, e.g. tumor vasculature, are particularly advantageous. In this study, such a combination therapy consisting of oncolytic VACV GLV-1h68, destroying tumor cells, and CPA, presumably targeting tumor vasculature, could successfully be established for the PC14PE6-RFP tumor model.

\section{Conclusions}

Our data demonstrate that combination treatment of GLV$1 \mathrm{~h} 68$ and CPA results in strongly enhanced antitumor efficacy in the PC14PE6-RFP tumor model. Results presented here suggest that improved tumor control achieved by combining GLV-1h68 with CPA is due to the action of $\mathrm{CPA}$ on the tumor vasculature. Yet, the effect of CPA may be cancer cell specific as well as highly dose dependent and may also be mouse model specific. Nevertheless, these results justify the design of additional preclinical studies in other highly angiogenic tumor models. Moreover, the data shown here demonstrate that CPA as a chemotherapeutic agent can also be combined successfully with GLV-1h68 strain (GL-ONC1), which is currently evaluated in phase I/ II clinical trials as monotherapy and could be considered as combination therapy in human clinical trials.

\section{Additional files}

\begin{abstract}
Additional file 1: Histological analysis of CD68-positive immune cells in PC14PE6-RFP tumors. PC14PE6-RFP tumor-bearing mice were either i.v. injected with $1 \times 10^{7}$ pfu of GLV-1h68 or PBS as control and/or received i.p. injections with $140 \mathrm{mg} / \mathrm{kg}$ bodyweight CPA at day 0 and with $100 \mathrm{mg} / \mathrm{kg}$ bodyweight at days 1, 3 and 7 . Tumors were harvested 7 dpi. (A) Whole tumor cross-sections of PBS-, CPA-, GLV1h68- or combination-treated tumors were labelled with an anti-rat CD68 antibody (Abcam, Cambridge, UK) and a secondary DyLight 649-conjugated donkey anti-rat antibody (Dianova, Hamburg, Germany) to visualize the presence of CD68-positive leukocytes. All confocal images are representative examples for respective groups. (B) Mean fluorescence intensity of CD68-labelling was determined using Image J software (http://rsbweb.nih.gov/ij). For all experiments the mean value was calculated for 12 images (four images of three different PBS-, CPA-, GLV-1h68- or combination-treated tumors) and presented as mean values with standard deviations.

Additional file 2: Depletion of phagocytic cells by clodronate liposomes. PC14PE6-RFP tumor-bearing mice were either i.v. injected with $1 \times 10^{7}$ pfu of GLV-1h68 or PBS as control or received i.p. injections with 140 $\mathrm{mg} / \mathrm{kg}$ bodyweight CPA at day 0 and with $100 \mathrm{mg} / \mathrm{kg}$ bodyweight at days 1, 3 and 7 or i.p. injections with $200 \mu$ l Clodronate liposomes (CLIP) at days 0, 1, 3 and 7 post treatment start. Clodronate liposomes were obtained from clodronateliposomes.com ( $\mathrm{N}$. van Rooijen, Amsterdam, The Netherlands) at a concentration of $7 \mathrm{mg} / \mathrm{ml}$. Tumor growth was monitored for 14 days.
\end{abstract}

\section{Abbreviations}

CPA: Cyclophosphamide; FBS: Fetal bovine serum; GFP: Green fluorescent protein; Hpi: Hours post infection; LIVP: (Lister strain from the Institute of Viral preparations, Moscow, Russia); MOI: Multiplicity of infection; MTT: 3-(4,5dimethylthiazol-2-yl)-2,5-diphenyltetrazolium bromide; Pfu: Plaque forming units; RFP: Red fluorescent protein; RUC: Renilla luciferase; s.d.: Standard deviation; VACV: Vaccinia virus.

\section{Competing interests}

$\mathrm{EH}$ and SW are recipients of postdoctoral fellowships of the University of Würzburg from a research service grant provided by Genelux Corporation. AAS is salaried employee of Genelux Corporation and has personal financial interests in Genelux Corporation. The funders had no role in study design, data collection and analysis or decision to publish. This work was supported by a research grant and a service grant from Genelux Corporation (R\&D facility in San Diego, CA, USA).

\section{Authors' contributions}

EH and SW designed the study, performed the experiments, statistical analyses and interpretation of data and wrote the manuscript. AAS participated in conceiving the study and writing the manuscript. All authors read and approved the final manuscript.

\section{Acknowledgements}

We thank Qian Zhang, Nanhai Chen, Terry Trevino and Jason Aguilar for providing GLV-1h68 and Frank Winkler for providing PC14PE6-RFP cells, Johanna Langbein for excellent technical support, Nanhai Chen for organizing analysis of protein samples by RBM, and other members of our laboratory for advice and support. The study was supported by grants from Genelux Corporation (R\&D facility in San Diego, CA, USA) awarded to the University of 
Wuerzburg, Germany. This publication was funded by the German Research Foundation (DFG) and the University of Wuerzburg in the funding programme Open Access Publishing.

\section{Author details}

'Department of Biochemistry, Biocenter, University of Wuerzburg, D-97074 Wuerzburg, Germany. ${ }^{2}$ Rudolf Virchow Center, Research Center for Experimental Biomedicine, University of Wuerzburg, D-97078, Wuerzburg, Germany. ${ }^{3}$ Institute for Molecular Infection Biology, University of Wuerzburg, D-97078 Wuerzburg, Germany. ${ }^{4}$ Department of Radiation Medicine and Applied Sciences and Center for Advanced Radiotherapy Technologies, University of California San Diego, La Jolla, San Diego, CA 92093, USA. ${ }^{5}$ Genelux Corporation, San Diego Science Center, 3030 Bunker Hill Streeet, Suite 310, San Diego, CA 92109, USA.

Received: 14 October 2013 Accepted: 10 July 2014

Published: 17 July 2014

\section{References}

1. Jemal A, Bray F, Center MM, Ferlay J, Ward E, Forman D: Global cancer statistics. CA Cancer J Clin 2011, 61:69-90.

2. Sun S, Schiller JH, Spinola M, Minna JD: New molecularly targeted therapies for lung cancer. J Clin Invest 2007, 117:2740-2750.

3. Jemal A, Siegel R, Ward E, Murray T, Xu J, Smigal C, Thun MJ: Cancer statistics, 2006. CA Cancer J Clin 2006, 56:106-130.

4. Cagle PT, Chirieac LR: Advances in treatment of lung cancer with targeted therapy. Arch Pathol Lab Med 2012, 136:504-509.

5. Chiocca EA: Oncolytic viruses. Nat Rev Cancer 2002, 2:938-950

6. Cattaneo R, Miest T, Shashkova EV, Barry MA: Reprogrammed viruses as cancer therapeutics: targeted, armed and shielded. Nat Rev Microbiol 2008, 6:529-540.

7. Vaha-Koskela MJ, Heikkila JE, Hinkkanen AE: Oncolytic viruses in cancer therapy. Cancer Lett 2007, 254:178-216.

8. Liu TC, Galanis E, Kirn D: Clinical trial results with oncolytic virotherapy: a century of promise, a decade of progress. Nat Clin Pract Oncol 2007, 4:101-117.

9. Shen $Y$, Nemunaitis J: Fighting cancer with vaccinia virus: teaching new tricks to an old dog. Mole Ther 2005, 11:180-195.

10. Thorne SH, Bartlett DL, Kirn DH: The use of oncolytic vaccinia viruses in the treatment of cancer: a new role for an old ally? Curr Gene Ther 2005, 5:429-443.

11. Chen NG, Szalay AA: Oncolytic vaccinia virus: a theranostic agent for cancer. Future Virol 2010, 5:763-784.

12. Zhang Q, Yu YA, Wang E, Chen N, Danner RL, Munson PJ, Marincola FM, Szalay AA: Eradication of solid human breast tumors in nude mice with an intravenously injected light-emitting oncolytic vaccinia virus. Cancer Res 2007, 67:10038-10046.

13. Hofmann E, Grummt F, Szalay AA: Vaccinia virus GLV-1 h237 carrying a Walker A motif mutation of mouse $\mathrm{Cdc} 6$ protein enhances human breast tumor therapy in mouse xenografts. Int J Oncol 2011, 38:871-878.

14. Seubert CM, Stritzker J, Hess M, Donat U, Sturm JB, Chen N, von Hof JM, Krewer B, Tietze LF, Gentschev I, Szalay AA: Enhanced tumor therapy using vaccinia virus strain GLV-1h68 in combination with a beta-galactosidaseactivatable prodrug seco-analog of duocarmycin SA. Cancer Gene Ther 2011, 18:42-52

15. Lin SF, Price DL, Chen CH, Brader P, Li S, Gonzalez L, Zhang Q, Yu YA, Chen N, Szalay AA, Fong Y, Wong RJ: Oncolytic vaccinia virotherapy of anaplastic thyroid cancer in vivo. J Clin Endocrinol Metab 2008, 93:4403-4407.

16. Kelly K, Woo Y, Brader P, Yu Z, Riedl C, Lin SF, Chen N, Yu YA, Rusch WW, Szalay AA, Fong Y: Novel oncolytic agent GLV-1h68 is effective against malignant pleural mesothelioma. Hum Gene Ther 2008, 19:774-782.

17. Yu Z, Li S, Brader P, Chen N, Yu YA, Zhang Q, Szalay AA, Fong Y, Wong RJ: Oncolytic vaccinia therapy of squamous cell carcinoma. Mol Cancer 2009, 8:45.

18. Yu YA, Galanis C, Woo Y, Chen N, Zhang Q, Fong Y, Szalay AA: Regression of human pancreatic tumor xenografts in mice after a single systemic injection of recombinant vaccinia virus GLV-1h68. Mol Cancer Ther 2009, 8:141-151.

19. Haddad D, Chen N, Zhang Q, Chen CH, Yu YA, Gonzalez L, Aguilar J, Li P, Wong J, Szalay AA, Fong Y: A novel genetically modified oncolytic vaccinia virus in experimental models is effective against a wide range of human cancers. Ann Surg Oncol 2012, Suppl 3:S665-S674.

20. Haddad D, Chen NG, Zhang Q, Chen CH, Yu YA, Gonzalez L, Carpenter SG, Carson J, Au J, Mittra A, Gonen M, Zanzonico PB, Fong Y, Szalay AA: Insertion of the human sodium iodide symporter to facilitate deep tissue imaging does not alter oncolytic or replication capability of a novel vaccinia virus. J Trans/ Med 2011, 9:36.

21. Chen N, Zhang Q, Yu YA, Stritzker J, Brader P, Schirbel A, Samnick S, Serganova I, Blasberg R, Fong Y, Szalay AA: A novel recombinant vaccinia virus expressing the human norepinephrine transporter retains oncolytic potential and facilitates deep-tissue imaging. Mol Med 2009, 15:144-151.

22. Gentschev I, Donat U, Hofmann E, Weibel S, Adelfinger M, Raab V, Heisig M, Chen N, Yu YA, Stritzker J, Szalay AA: Regression of human prostate tumors and metastases in nude mice following treatment with the recombinant oncolytic vaccinia virus GLV-1h68. J Biomed Biotechnol 2010, 2010:489759.

23. Sturm JB, Hess M, Weibel S, Chen NG, Yu YA, Zhang Q, Donat U, Reiss C, Gambaryan S, Krohne G, Stritzker J, Szalay AA: Functional hyper-IL-6 from vaccinia virus-colonized tumors triggers platelet formation and helps to alleviate toxicity of mitomycin C enhanced virus therapy. J Trans/ Med 2012, 10:9.

24. Frentzen A, Yu YA, Chen N, Zhang Q, Weibel S, Raab V, Szalay AA: AntiVEGF single-chain antibody GLAF-1 encoded by oncolytic vaccinia virus significantly enhances antitumor therapy. Proc Natl Acad Sci U S A 2009, 106:12915-12920.

25. He S, Li P, Chen CH, Bakst RL, Chernichenko N, Yu YA, Chen N, Szalay AA Yu Z, Fong Y, Wong RJ: Effective oncolytic vaccinia therapy for human sarcomas. J Surg Res 2011, 175:e53-e60.

26. Gentschev I, Muller M, Adelfinger M, Weibel S, Grummt F, Zimmermann M, Bitzer M, Heisig M, Zhang Q, Yu YA, Chen NG, Stritzker J, Lauer UM, Szalay AA: Efficient colonization and therapy of human hepatocellular carcinoma (HCC) using the oncolytic vaccinia virus strain GLV-1h68. PLOS One 2011, 6:e22069.

27. Gentschev I, Stritzker J, Hofmann E, Weibel S, Yu YA, Chen N, Zhang Q, Bullerdiek J, Nolte I, Szalay AA: Use of an oncolytic vaccinia virus for the treatment of canine breast cancer in nude mice: preclinical development of a therapeutic agent. Cancer Gene Ther 2009, 16:320-328.

28. Gentschev I, Ehrig K, Donat U, Hess M, Rudolph S, Chen N, Yu YA, Zhang Q, Bullerdiek J, Nolte I, Stritzker J, Szalay AA: Significant growth inhibition of canine mammary carcinoma xenografts following treatment with oncolytic vaccinia virus GLV-1h68. J Oncol 2010, 2010:736907.

29. Ottolino-Perry K, Diallo JS, Lichty BD, Bell JC, McCart JA: Intelligent design: combination therapy with oncolytic viruses. Mol Ther 2010, 18:251-263.

30. Advani SJ, Buckel L, Chen NG, Scanderbeg DJ, Geissinger U, Zhang Q, Yu YA, Aguilar RJ, Mundt A, Szalay AA: Preferential replication of systemically delivered oncolytic vaccinia virus in focally irradiated glioma xenografts. Clin Cancer Res 2012, 18:2579-2590.

31. Aghi M, Chou TC, Suling K, Breakefield XO, Chiocca EA: Multimodal cancer treatment mediated by a replicating oncolytic virus that delivers the oxazaphosphorine/rat cytochrome $\mathrm{P} 4502 \mathrm{~B} 1$ and ganciclovir/herpes simplex virus thymidine kinase gene therapies. Cancer Res 1999 59:3861-3865

32. Tyminski E, Leroy S, Terada K, Finkelstein DM, Hyatt JL, Danks MK, Potter PM, Saeki Y, Chiocca EA: Brain tumor oncolysis with replication-conditional herpes simplex virus type 1 expressing the prodrug-activating genes, CYP2B1 and secreted human intestinal carboxylesterase, in combination with cyclophosphamide and irinotecan. Cancer Res 2005, 65:6850-6857

33. Fulci G, Breymann L, Gianni D, Kurozomi K, Rhee SS, Yu J, Kaur B, Louis DN, Weissleder R, Caligiuri MA, Chiocca EA: Cyclophosphamide enhances glioma virotherapy by inhibiting innate immune responses. Proc Natl Acad Sci U S A 2006, 103:12873-12878.

34. Ikeda K, Ichikawa T, Wakimoto H, Silver JS, Deisboeck TS, Finkelstein D, Harsh GR, Louis DN, Bartus RT, Hochberg FH, Chiocca EA: Oncolytic virus therapy of multiple tumors in the brain requires suppression of innate and elicited antiviral responses. Nat Med 1999, 5:881-887.

35. Currier MA, Gillespie RA, Sawtell NM, Mahller YY, Stroup G, Collins MH, Kambara H, Chiocca EA, Cripe TP: Efficacy and safety of the oncolytic herpes simplex virus rRp450 alone and combined with cyclophosphamide. Mol Ther 2008, 16:879-885.

36. Li H, Zeng Z, Fu X, Zhang X: Coadministration of a herpes simplex virus-2 based oncolytic virus and cyclophosphamide produces a synergistic 
antitumor effect and enhances tumor-specific immune responses. Cancer Res 2007, 67:7850-7855.

37. Thomas MA, Spencer JF, Toth K, Sagartz JE, Phillips NJ, Wold WS: Immunosuppression enhances oncolytic adenovirus replication and antitumor efficacy in the Syrian hamster model. Mol Ther 2008, 16:1665-1673.

38. Cerullo V, Diaconu I, Kangasniemi L, Rajecki M, Escutenaire S, Koski A, Romano V, Rouvinen N, Tuuminen T, Laasonen L, Partanen K, Kauppinen S, Joensuu T, Oksanen M, Holm SL, Haavisto E, Karioja-Kallio A, Kanerva A, Pesonen S, Arstila PT, Hemminki A: Immunological effects of low-dose cyclophosphamide in cancer patients treated with oncolytic adenovirus. Mol Ther 2011, 19:1737-1746.

39. Kottke T, Thompson J, Diaz RM, Pulido J, Willmon C, Coffey M, Selby P, Melcher A, Harrington K, Vile RG: Improved systemic delivery of oncolytic reovirus to established tumors using preconditioning with cyclophosphamide-mediated Treg modulation and interleukin-2. Clin Cancer Res 2009, 15:561-569.

40. Qiao J, Wang H, Kottke T, White C, Twigger K, Diaz RM, Thompson J, Selby P, de Bono J, Melcher A, Pandha H, Coffey M, Vile R, Harrington K: Cyclophosphamide facilitates antitumor efficacy against subcutaneous tumors following intravenous delivery of reovirus. Clin Cancer Res 2008, $14: 259-269$

41. Lun $X Q$, Jang JH, Tang N, Deng H, Head R, Bell JC, Stojdl DF, Nutt CL, Senger DL, Forsyth PA, McCart JA: Efficacy of systemically administered oncolytic vaccinia virotherapy for malignant gliomas is enhanced by combination therapy with rapamycin or cyclophosphamide. Clin Cancer Res 2009, 15:2777-2788.

42. Kienast $Y$, von Baumgarten L, Fuhrmann M, Klinkert WE, Goldbrunner R, Herms J, Winkler F: Real-time imaging reveals the single steps of brain metastasis formation. Nat Med 2010, 16:116-122.

43. Patten SG, Adamcic U, Lacombe K, Minhas K, Skowronski K, Coomber BL: VEGFR2 heterogeneity and response to anti-angiogenic low dose metronomic cyclophosphamide treatment. BMC Cancer 2010, 10:683.

44. Browder T, Butterfield CE, Kraling BM, Shi B, Marshall B, O'Reilly MS, Folkman $\mathrm{J}$ : Antiangiogenic scheduling of chemotherapy improves efficacy against experimental drug-resistant cancer. Cancer Res 2000, 60:1878-1886.

45. Daenen LG, Shaked Y, Man S, Xu P, Voest EE, Hoffman RM, Chaplin DJ, Kerbel RS: Low-dose metronomic cyclophosphamide combined with vascular disrupting therapy induces potent antitumor activity in preclinical human tumor xenograft models. Mol Cancer Ther 2009, 8:2872-2881.

46. Dawson DW, Pearce SF, Zhong R, Silverstein RL, Frazier WA, Bouck NP: CD36 mediates the In vitro inhibitory effects of thrombospondin-1 on endothelial cells. J Cell Biol 1997, 138:707-717.

47. Gupta K, Gupta P, Wild R, Ramakrishnan S, Hebbel RP: Binding and displacement of vascular endothelial growth factor (VEGF) by thrombospondin: effect on human microvascular endothelial cell proliferation and angiogenesis. Angiogenesis 1999, 3:147-158.

48. Galon J, Angell HK, Bedognetti D, Marincola FM: The continuum of cancer immunosurveillance: prognostic, predictive, and mechanistic signatures. Immunity 2013, 39:11-26.

49. Blanchard F, Duplomb L, Baud'huin M, Brounais B: The dual role of IL-6type cytokines on bone remodeling and bone tumors. Cytokine Growth Factor Rev 2009, 20:19-28.

50. Lacreusette A, Lartigue A, Nguyen JM, Barbieux I, Pandolfino MC, Paris F, Khammari A, Dreno B, Jacques Y, Blanchard F, Godard A: Relationship between responsiveness of cancer cells to Oncostatin M and/or IL- 6 and survival of stage III melanoma patients treated with tumour-infiltrating lymphocytes. J Pathol 2008, 216:451-459.

51. Chipoy C, Berreur M, Couillaud S, Pradal G, Vallette F, Colombeix C, Redini F, Heymann D, Blanchard F: Downregulation of osteoblast markers and induction of the glial fibrillary acidic protein by oncostatin $M$ in osteosarcoma cells require PKCdelta and STAT3. J Bone Miner Res 2004 19:1850-1861.

52. Goswami S, Sahai E, Wyckoff JB, Cammer M, Cox D, Pixley FJ, Stanley ER, Segall JE, Condeelis JS: Macrophages promote the invasion of breast carcinoma cells via a colony-stimulating factor-1/epidermal growth factor paracrine loop. Cancer Res 2005, 65:5278-5283.

53. Hyka N, Dayer JM, Modoux C, Kohno T, Edwards CK 3rd, Roux-Lombard P, Burger D: Apolipoprotein A-I inhibits the production of interleukin-1beta and tumor necrosis factor-alpha by blocking contact-mediated activation of monocytes by T lymphocytes. Blood 2001, 97:2381-2389.

54. Barter PJ, Nicholls S, Rye KA, Anantharamaiah GM, Navab M, Fogelman AM: Antiinflammatory properties of HDL. Circ Res 2004, 95:764-772.
55. Epand RM, Stafford A, Leon B, Lock PE, Tytler EM, Segrest JP, Anantharamaiah GM: HDL and apolipoprotein A-I protect erythrocytes against the generation of procoagulant activity. Arterioscler Thromb 1994, 14:1775-1783.

56. Chen Q, Massague J: Molecular pathways: VCAM-1 as a potential therapeutic target in metastasis. Clin Cancer Res 2012, 18:5520-5525.

57. Zheng Y, Yang W, Aldape K, He J, Lu Z: Epidermal Growth Factor (EGF)-enhanced Vascular Cell Adhesion Molecule-1 (VCAM-1) expression promotes macrophage and glioblastoma cell interaction and tumor cell invasion. J Biol Chem 2013, 288:31488-31495.

58. Wu TC: The role of vascular cell adhesion molecule-1 in tumor immune evasion. Cancer Res 2007, 67:6003-6006.

59. Lin KY, Lu D, Hung CF, Peng S, Huang L, Jie C, Murillo F, Rowley J, Tsai YC, He L, Kim DJ, Jaffee E, Pardoll D, Wu TC: Ectopic expression of vascular cell adhesion molecule-1 as a new mechanism for tumor immune evasion. Cancer Res 2007, 67:1832-1841.

60. Yano S, Shinohara H, Herbst RS, Kuniyasu H, Bucana CD, Ellis LM, Fidler IJ: Production of experimental malignant pleural effusions is dependent on invasion of the pleura and expression of vascular endothelial growth factor/vascular permeability factor by human lung cancer cells. Am J Pathol 2000, 157:1893-1903.

61. Weibel S, Hofmann E, Basse-Luesebrink TC, Donat U, Seubert C, Adelfinger M, Gnamlin P, Kober C, Frentzen A, Gentschev I, Jakob PM, Szalay AA: Treatment of malignant effusion by oncolytic virotherapy in an experimental subcutaneous xenograft model of lung cancer. J Trans/ Med 2013, 11:106.

62. Weibel S, Raab V, Yu YA, Worschech A, Wang E, Marincola FM, Szalay AA: Viral-mediated oncolysis is the most critical factor in the late-phase of the tumor regression process upon vaccinia virus infection. BMC Cancer 2011, 11:68

doi:10.1186/1479-5876-12-197

Cite this article as: Hofmann et al:: Combination treatment with oncolytic Vaccinia virus and cyclophosphamide results in synergistic antitumor effects in human lung adenocarcinoma bearing mice. Journal of Translational Medicine 2014 12:197.

\section{Submit your next manuscript to BioMed Central and take full advantage of:}

- Convenient online submission

- Thorough peer review

- No space constraints or color figure charges

- Immediate publication on acceptance

- Inclusion in PubMed, CAS, Scopus and Google Scholar

- Research which is freely available for redistribution

Submit your manuscript at www.biomedcentral.com/submit
C) Biomed Central 